\title{
LIQUID MIGRATION IN THE PASTE AS THE RESULT OF CONSOLIDATION
}

\author{
ULIČNÁ Miriam ${ }^{1}$, FEKETE Roman ${ }^{1 *}$, LIKAVČAN Adam¹, PECIAR Marián ${ }^{1}$ \\ ${ }^{I}$ Slovak University of Technology in Bratislava, Faculty of Mechanical Engineering, Institute of Process \\ Engineering, Námestie Slobody 17,812 31 Bratislava, Slovakia, e-mail: roman.fekete@stuba.sk
}

\begin{abstract}
The processing of various powder materials is often done by an extrusion process; the powders being formed into a paste by the addition of a liquid substance. During extrusion, by reason of the extrusion pressure, some properties of the paste are changing, which affect its rheology and thus the extrusion itself. One of the phenomena is the movement of the liquid phase. This paper is focused on monitoring this phenomenon using model material in a simple test device. Its design simulates the effect of pressure in the extruder. The results of the measurements provide a picture of the movement of the liquid phase under the influence of the pressure in the porous skeleton formed by the powder material.
\end{abstract}

KEYWORDS: extrusion, paste, porosity, liquid phase migration

\section{Introduction}

In the area of Chemical and Food Industry Technologies substances in the form of powders or granules are used very often. These substances have common properties that meet the definition of a particulate substance. Particulate matters are substances composed of mutually contacting solid particles (solid phase), gaseous and / or liquid phase. The gaseous or liquid phase fills the pores of the skeleton formed by the solid particles. If the liquid phase significantly predominates over the gaseous phase, that substances are called pastes. A particulate matter can be considered as a whole consisting of individual particles that are in contact with each other. From this point of view, it is possible to define voidage and porosity [1].

The voidage is the space between the interacting particles in the particulate matter. The porosity then only applies to the individual particles. The voidage may vary in connection with the consolidation of the particulate matter by extrusion pressure. Since pastes are materials made up of at least two phases, it is important that their flow, extrusion, be described with terms of the movement of both phases [2].

Due to liquid movement through the holes of the die, the rheological properties of the paste are changed and thus the whole extrusion process as well as the quality of the product is affected. Therefore, it is essential to understand the properties of the paste and the phenomena associated with the movement of the liquid phase during extrusion. One of the basic ways to test the properties of the paste from the point of view of liquid migration is uniaxial compression. [3]. The paste is placed in a cylinder which has a sieve at the bottom and a certain pressure of the piston acts on the top.

Due to the pressure, the paste is consolidated and the liquid moves in the pores towards the sieve. Tests are able to performed for different pressures and consolidation times. The result is a redistribution of the liquid in the paste due to the pressure before the paste is set in motion and is forced through the die. 


\section{Theoretical analysis}

The pressure required for extrusion is not high. Usually it is only up to a few MPa. Nevertheless, it can significantly affect the extrusion process due to consolidation. From the point of view of paste consolidation, it is necessary to monitor the following quantities and their influence on the extrusion process and the quality of the product.

\subsection{Porosity}

The paste, as a multiphase system, consists of a skeleton made of powder materials. The individual grains are in contact with the surrounding grains. The spaces between them can be called pores, regardless of their shape, mutual size or degree of interconnection [4]. Because of this work is focused on the migration of liquid in the porous materials, it is important to make focus on porous material as an environment of the transport process. From the point of view of paste extrusion, it can be assumed that macropores and capillary pores have a significant effect on the redistribution of the liquid in the paste. Macropores form between contacting grains [5]. Due to the compressibility of the granular skeleton, during the application of the extrusion pressure, it can change into capillary pores. Therefore, the phenomenon called liquid phase migration in the paste can also vary depending on the extrusion pressure.

The porosity depends on the geometrical and physical properties of the solid phase (grain size, the shape of the grains) that forms the particulate matter and the degree of its dynamic stress.

Porosity of granular material $\varepsilon_{S}$, resp. $\mathcal{E}_{v}$ (dry or wet) is defined as the ratio of the total pore volume $V_{p}$ to the total volume of granular material $V_{s}$ resp. $V_{v}[6]$. The porosity of the dry granular material is:

$$
\varepsilon_{s}=\frac{V_{p}}{V_{s}}
$$

The porosity of the wet granular material is:

$$
\mathcal{E}_{v}=\frac{V_{p}}{V_{v}}
$$

The density of dry granular material is:

$$
\rho_{s}=\left(1-\varepsilon_{s}\right) \rho_{1}
$$

Density of liquid unsaturated granular material, i.e. when all pores are filled with liquid is:

$$
\rho_{v}=\left(1-\varepsilon_{v}\right) \rho_{1}+\varepsilon_{v} \rho_{s}
$$

\subsection{Moisture in porous material}

The liquid phase in pastes is most often formed by addition a water. To form the paste, it is necessary, the water to fill the pores either partially or completely [7]. The amount of water relative to a unit weight or unit volume is generally called the moisture of the substance.

a) absolute weight fraction

$$
w=\frac{m_{w}}{m_{v}}=\frac{m_{v}-m_{s}}{m_{v}}
$$


b) relative weight fraction

$$
W=\frac{m_{w}}{m_{s}}=\frac{m_{v}-m_{s}}{m_{s}}
$$

\subsection{Density}

Assuming that the basic particles dried to constant weight are considered to be incompressible of density $\rho_{1}$, the density of the dry granular material is:

$$
\rho_{s}=\frac{m_{s}}{V_{s}}
$$

The density of the wet granular material is analogous to:

$$
\rho_{v}=\frac{m_{v}}{V_{v}}
$$

\subsection{Degree of saturation}

The degree of saturation of the granular material by the liquid $S$, is defined as the ratio of the volume of the free liquid $V_{p w}$ to the total volume of the pores $V_{p}$, i.e.:

$$
S=\frac{V_{p w}}{V_{p}}
$$

Based on the knowledge of the density of the basic particles $\rho_{1}$, the density of the wet material $\rho_{\mathrm{V}}$, the density of the liquid $\rho_{2}$ and the free moisture content $W$, the following balance relations is applied:

Porosity of wet granular material:

$$
\mathcal{E}_{v}=1-\frac{\rho_{v}}{\rho_{1}} \cdot \frac{1}{1+W}
$$

Degree of saturation:

$$
S=\rho_{v} \frac{\rho_{1}}{\rho_{2}} \cdot \frac{W}{\rho_{1}(1+W)-\rho_{v}}
$$

\section{Experimental}

During extrusion, the liquid phase movement occurs in three ways:

1. Collection the liquid phase around the die as droplets on the surface of the extrudate.

2. The extrusion pressure is higher at lower speeds than at high speeds, which is due to the fact that at lower paste flow rates the paste is in the extruder for a longer time, thus creating better conditions for its consolidation.

3. A fine liquid phase penetration can cause the significant increase in the tension in the solid phase.

Burbidge in his work investigated the movement of the liquid phase [8,9]. The extrusion process is affected by the movement of the liquid phase, which should be kept to a minimum. When the paste sample is under pressure, the liquid is redistributed in the pores of the particulate skeleton. This phenomenon can be investigated using the uniaxial compression preparation (Fig. 1a). 


\subsection{Apparatus}

The experimental device consists of a cylinder (3) which is filled with paste. The bottom of the cylinder is closed by a filter baffle (2) placed on a perforated grate (1). A piston (6) acts on the paste from the upper part, while there is a rubber seal (4) between the surface of the paste and the piston. The piston creates a consolidation pressure $p$, which is caused by the weights (7).The pressure $p$ is constant during each one set of tests. The test is defined by the time interval $t$, during which the paste is consolidated by the pressure $p$. During consolidation, the pores of the granular skeleton are reorganized too. The paste material is highest compressed at the piston, where the porosity is changed the most.

Due to the lateral friction against the surface of the cylinder, the effect of the pressure towards the filter baffle decreases thus the porosity change is smaller. This phenomenon creates conditions for the migration of the liquid phase towards the filter baffle.

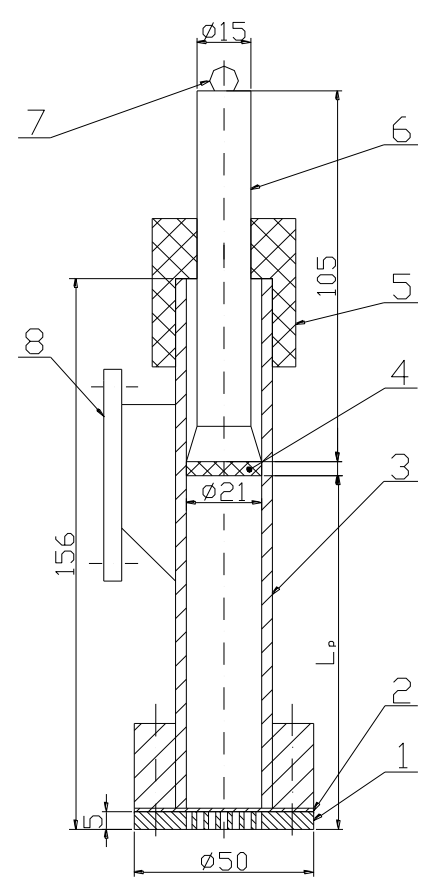

a)

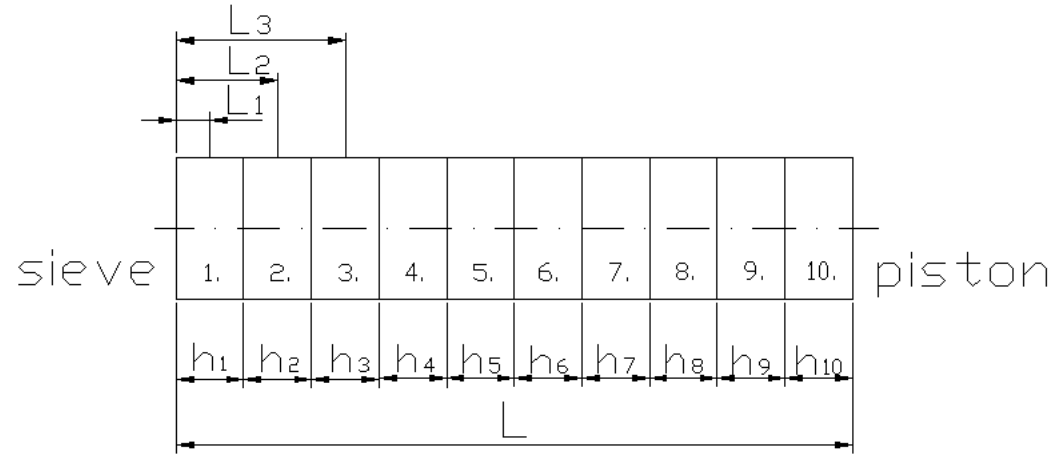

b)

calculation of relative length:

$$
i=\frac{L_{n}}{L}
$$

if: $L_{1}=\frac{h_{1}}{2}$, pre $L_{2}=h_{1}+\frac{h_{2}}{2}$, pre $L_{3}=h_{1}+h_{2}+\frac{h_{3}}{2}$, etc.

\begin{tabular}{|l|c|c|c|c|c|}
\hline Consolidation pressure $p[\mathrm{MPa}]$ & 0,45 & 1,0 & 2,0 & 3,0 & 4,0 \\
\hline \multirow{2}{*}{ Consolidation time $t[\mathrm{~s}]$} & \multicolumn{5}{|c|}{60} \\
& \multicolumn{5}{|c}{300} \\
\hline
\end{tabular}

c)

Fig. 1 Experimental apparatus

a) de-watering device: 1 . flange, the sieve is not supported, 2 . filter barrier with mesh size $0,25 \times 0,25 \mathrm{~mm}$, wire with diameter $0,25 \mathrm{~mm}$, 3. cylinder, 4. rubber seal 5. lid, 6 . piston, 7. weights, 8 . flange suitable for fixing device;

b) paste distribution map after test; c) table of consolidation pressures and times.

The experimental analysis of liquid phase migration consists of two steps. In the first step, the consolidation of the paste is performed by the pressure $p$ during the time interval $t$. In the second step, the paste is then removed from the roller and cut in particular same controlled volumes. Each volume is measured and weighed as wet volume then leave to dry and reweighed again. The results are represented in the form of figures (Fig. 3-6) and processed according to relations 1-11. 
The table in Fig. 1 shows the consolidation pressures and consolidation times that combined with each other. Each combination was repeated three times.

The paste was made from very finely ground limestone by adding water in a ratio of an absolute weight fraction $w=0,167$.

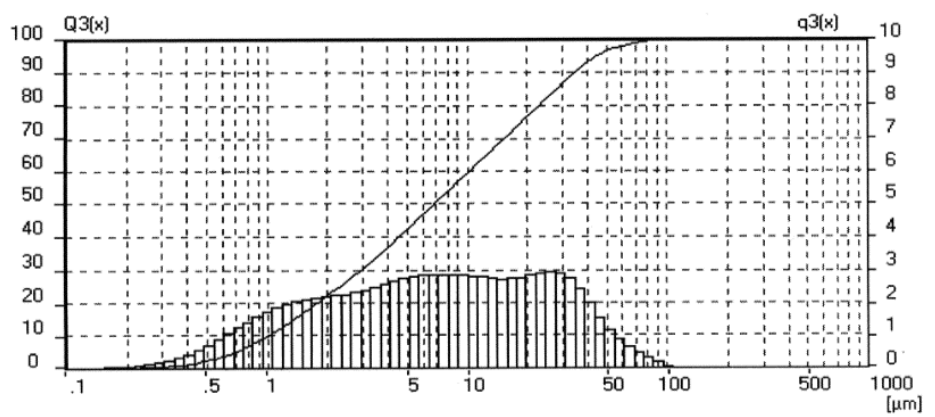

Fig. 2 Particle size distribution very finely ground limestone EKOCELL VITA 7,

Cementáreň Lietavská Lúčka, a.s., Density of particles $\rho_{\check{c}}=2762,6 \mathrm{~kg} \cdot \mathrm{m}^{-3}$

\section{$4 \quad$ Results and discussion}

The experiments were focused primarily on monitoring the change in moisture of the paste $w$ along the length of the sample, from the piston to the filter baffle. The tests show the results for two consolidation times and five consolidation pressures values according to the table in the figure (Fig. 1c).

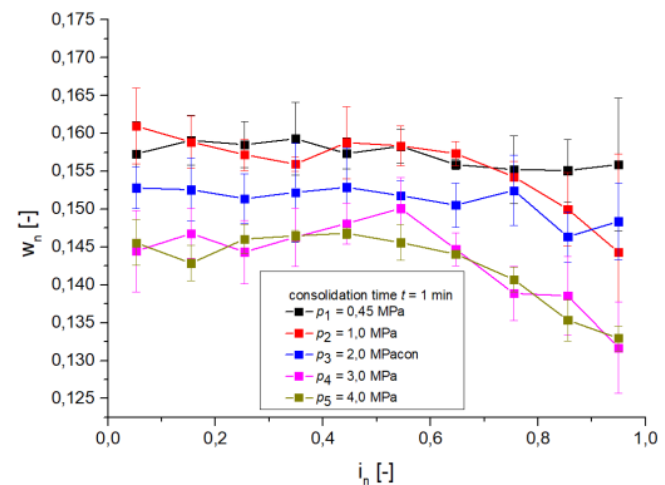

a)

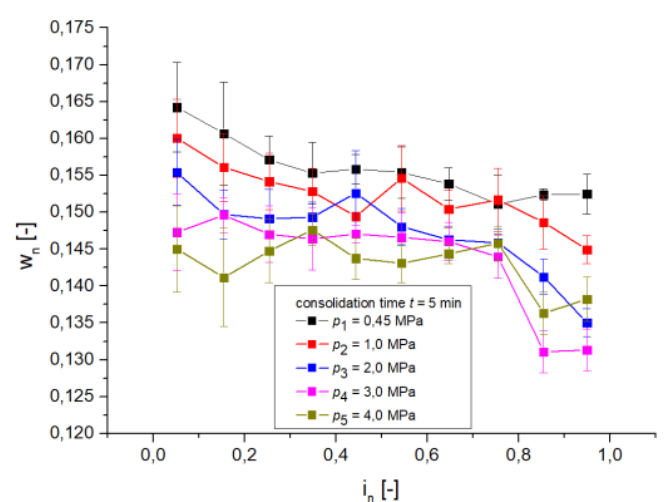

b)

Fig. 3 The absolute humidity of the sample dependent on the relative length and pressure $w_{n}=f\left(i_{n}, p\right)$, for consolidation times a) $t=1 \mathrm{~min}$; b) $t=5 \mathrm{~min}$

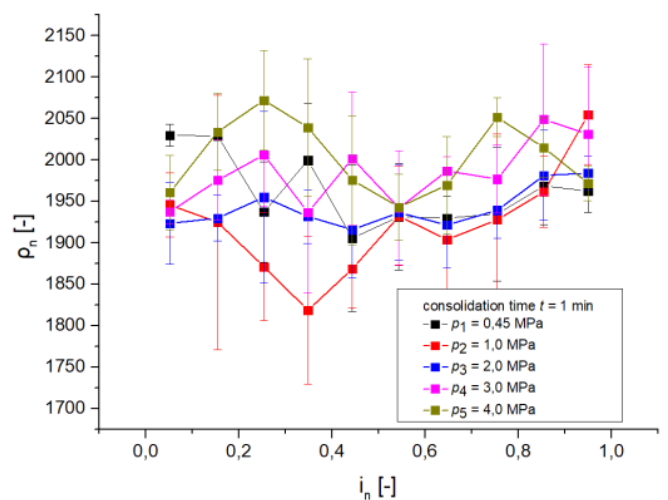

a)

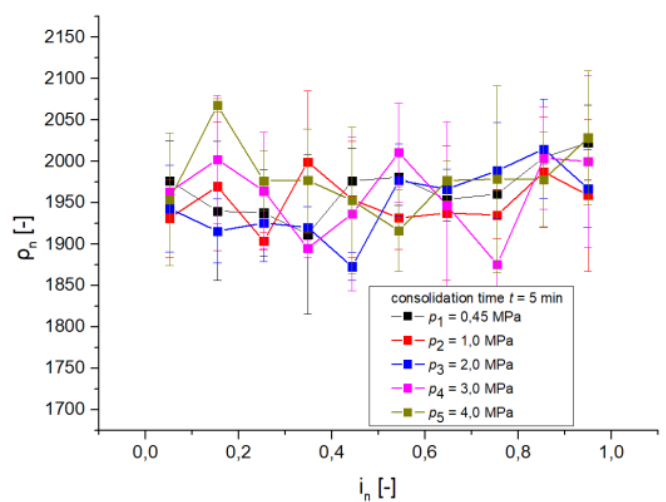

b)

Fig. 4 The paste density dependent on relative length and pressure $\rho_{\mathrm{n}}=f\left(i_{n}, p\right)$, for 


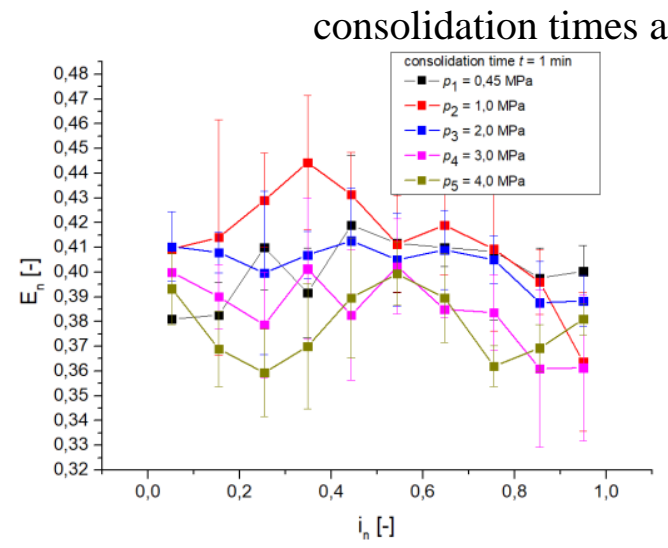

a)

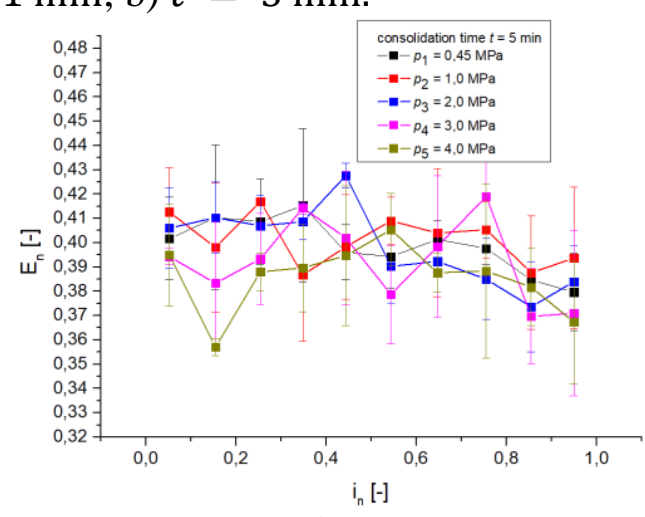

b)

Fig. 5 The sample porosity dependent on relative sample length and pressure $\varepsilon_{n}=$ $f\left(i_{n}, p\right)$, for consolidation times a) $t=1 \mathrm{~min}$; b) $t=5 \mathrm{~min}$.

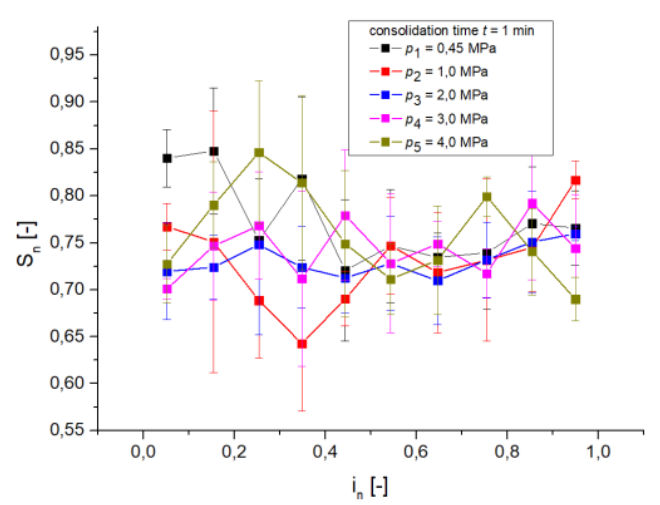

a)

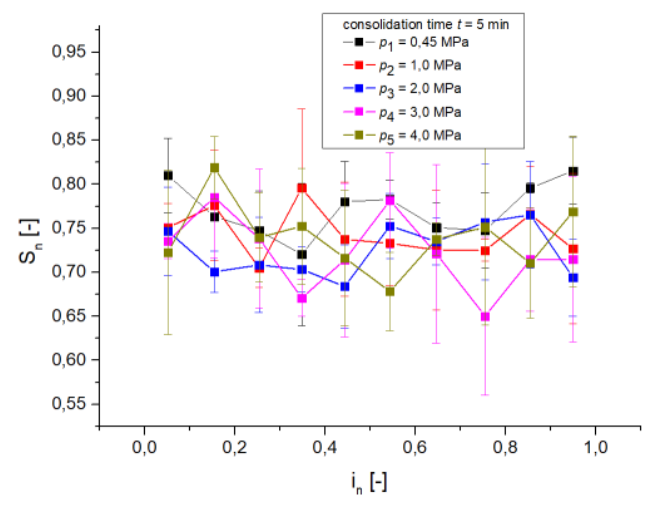

b)

Fig. 6 The degree of liquid saturation of the particles dependent on the relative length of the sample and the pressure $S_{n}=f\left(i_{n}, p\right)$, for consolidation times a) $t=1 \mathrm{~min}$; b) $t=5 \mathrm{~min}$.

The results of the test illustrate the consolidation time $t$ and the consolidation pressure $p$ for the humidity change (Fig. 3) that shows similar trends during the change in humidity along the length of the sample. Because of the consolidation of the sample, the liquid is moved towards the filter baffle, which allows leakage from the paste placed in the test preparation. The length of the consolidation time $t$ has no significant effect on the redistribution of the liquid in the sample. However, the effect of pressure $p$ is significant.

The effect of the consolidation time has an influence on change in the density $\rho_{n}$, the porosity $E_{n}$ and the degree of saturation $S_{n}$. When the degree of saturation increases, consolidation of the paste occurs, that is represented by a change in its density along the length of the sample (Fig. 4). In general, it can be stated that with increasing consolidation time, the monitored parameters are more homogeneous. Simultaneously, the scattering of the parameters of density $\rho_{n}$, porosity $E_{n}$ and degree of saturation $S_{n}$ is reduced, these parameters being less dependent on the length of the sample. This is due to the fact that the particulate matters, and especially the pastes formed from them, display behaviour which is time-dependent. Therefore, as the consolidation time is extended, the particular components of the paste, i.e. the granular skeleton and the liquid phase, are given the time needed to carry out the consolidation 
It is possible to notice the largest density variance for $i=0,0$ to $i=0,5$, with the density tending to move from higher to smaller values. The scattering interval of the density values decreases, with the smallest being approximately at $i=0,55$, i.e. in the middle of the sample. It can be assumed that this is due to the friction of the paste against the wall of the preparation. In position $i=0,0$, the piston pushes directly on the paste, consequently the pressure is transferred directly to it and the paste is consolidated.

Towards the centre of the length of the sample, the length increases, and thus also the area on which the paste is in contact with the jacket. Therefore, part of the pressure from the piston is used to overcome friction and not to consolidate the sample. In addition, another part of the pressure is used to overcome the hydraulic resistance when the fluid moves in the pores. In the picture (Fig. 3) is possible to find out that in this interval no significant decrease in humidity is noticed. Decrease occurs only after this position, towards the filter baffle. This phenomenon creates conditions where the liquid in the pores does not allow further consolidation of the sample and the density of the paste is the lowest here.

From this position, towards the filter barrier, the density increases again, while the moisture of the paste decreases. This is due to the fact that the distance towards the filter baffle decreases and also the hydraulic resistance to the movement of the fluid decreases too. The liquid moves outwards through the filter baffle easier. As a result, the hydraulic pressure in the pores also decreases and better conditions are created for the consolidation of the granular skeleton. This results in a decrease in porosity (Fig. 5), while the degree of saturation does not change significantly (Fig. 6).

\section{CONCLUSION}

The extrusion is the most commonly used process in which is very significant to maintain the homogeneity of the paste, especially with regard to the content of the liquid phase in the paste due to the movement of the paste through the different zones of the extruder. Testing this phenomenon of liquid phase migration in the extruder is complicated. Therefore, a simple test is performed to evaluate this phenomenon, which makes it possible to describe the properties of the paste through whole extrusion process. These experiments confirm the fact that fluid migration is a phenomenon that is associated with a pressure gradient in the paste. Nevertheless, this is a basic condition for extrusion. Therefore, it can be expected that the paste changes rheological properties during extrusion, mainly in terms of how it could adversely affect redistribution of liquid phase in the direction of movement in the extruder.

The results show that the effect of extrusion pressure, which affects the redistribution of the liquid phase, the porosity and the density of the paste, is significant. Another substantial parameter is the time during which the paste is under pressure. As it grows, the consolidation of the paste increases and the phenomena associated with it become more pronounced. Therefore, it is important to take into account the speed of the paste extrusion when selecting the specific process parameters of the extruder.

\section{ACKNOWLEDGEMENTS}

The authors wish to acknowledge the Ministry of Education, Science, Research and Sport of the Slovak Republic for the financial support of this research by grant KEGA 036STU-4/2020.

\section{LIST OF SYMBOLS}

$\begin{array}{lll}m_{s} & \text { weight of material after drying } & \mathrm{kg} \\ m_{v} & \text { weight of wet material before drying } & \mathrm{kg} \\ m_{w} & \text { weight of free moisture evaporated during drying } & \mathrm{kg}\end{array}$


$\begin{array}{lll}p & \text { pressure } & \mathrm{Pa}\end{array}$

$t$ time interval s

$w \quad$ absolute weight fraction $\quad 1$

$S \quad$ degree of saturation 1

$V_{s} \quad$ total volume of dry material, including the volume of pores between the particles $\mathrm{m}^{3}$

$V_{v} \quad$ total volume of wet material, including the volume of pores between the particles

$W \quad$ relative weight fraction

$\varepsilon_{v} \quad$ porosity of wet granular material

$\varepsilon_{s} \quad$ porosity of the dry granular material

$\rho_{s} \quad$ specific gravity of the liquid

$\rho_{1} \quad$ density of basic particles

$\rho_{2} \quad$ density of a fluid

$\mathrm{m}^{3}$
1
1
1
$\mathrm{~kg} \cdot \mathrm{m}^{-3}$
$\mathrm{~kg} \cdot \mathrm{m}^{-3}$
$\mathrm{~kg} \cdot \mathrm{m}^{-3}$

\section{REFERENCES}

[1] Feda, J. “Základy mechaniky partikulárních látek“, 1.vyd., Academia Praha, 1997.

[2] Benbow, J, Bridgwater, J. "Paste flow and extrusion", Clarendon press. Oxford, 176 p., 1993. ISBN 9780198563389.

[3] Kutílek, M. "Vlhkost' pórovitých materiálu“, Praha: SNTL - Nakladatelství technické literatúry, 1984.

[4] Paciga, A., Jaššo, I. "Kohézne vlastnosti vlhkých aglomerátov sulfenaxu CB. Kandidátska dizertačná práca“, 1979. (In Slovak)

[5] Macho, O., Čierny, M., Gabrišová, L', Juriga, M., Ružinský, R., Peciar, P. “Dynamic Image Analysis to Determine Granule Size and Shape, for Selected High Shear Granulation Process Parameters", Strojnícky časopis - Journal of Mechanical Engineering 69 (4), pp. 57 - 64, 2019. DOI: 10.2478/scjme-2019-0043

[6] Peciar, P., Juriga, M. Guštafík, A., Kohútová, M., Jeszó, K. "Procesné strojníctvo: Príklady”, Bratislava: Spektrum STU, 2021. ISBN 978-80-227-5081-3 (In Slovak)

[7] Peciar, P., Eckert, M., Fekete, R., Hrnčiar, V. “Analysis of pharmaceutical excipient MCC Avicel PH102 using compaction equations”, Strojnícky časopis - Journal of Mechanical Engineering 66 (1), pp. 65 - 82, 2016. DOI: 10.1515/scjme-2016-0012

[8] Burbidge, A., Bridgwater, J. "The single screw extrusion of pastes". Chemical Engineering Science 50 (16), pp. 2531 - 2543, 1995.

[9] Burbidge, A., Bridgwater, J., Saracevic, Z. "Liquid phase migration in paste extrusion", Transactions of the Institution of Chemical Engineers, , Part A (Chemical Engineering Research and Design) 73, pp. 810 - 816, 1995. 